Canadian University Music Review

Canadian University Music Review

Revue de musique des universités canadiennes

\title{
Healey Willan's Quest for a String Quartet
}

\section{Frederick R.C. Clarke}

Numéro 2, 1981

URI : https://id.erudit.org/iderudit/1013749ar

DOI : https://doi.org/10.7202/1013749ar

Aller au sommaire du numéro

Éditeur(s)

Canadian University Music Society / Société de musique des universités

canadiennes

ISSN

0710-0353 (imprimé)

2291-2436 (numérique)

Découvrir la revue

Citer cet article

Clarke, F. R. (1981). Healey Willan's Quest for a String Quartet. Canadian University Music Review / Revue de musique des universités canadiennes, (2), 166-176. https://doi.org/10.7202/1013749ar

All Rights Reserved (C Canadian University Music Society / Société de musique des universités canadiennes, 1981
Ce document est protégé par la loi sur le droit d'auteur. L'utilisation des services d'Érudit (y compris la reproduction) est assujettie à sa politique d'utilisation que vous pouvez consulter en ligne.

https://apropos.erudit.org/fr/usagers/politique-dutilisation/ 


\title{
HEALEY WILLAN'S QUEST FOR A STRING QUARTET
}

\author{
Frederick R.C. Clarke
}

Healey Willan's activity as a composer of chamber music dates mainly from the earlier part of his career, an activity which culminated in the years 1915-16 (by which time the composer was living in Canada) with the appearance of his three greatest accomplishments in the realm of chamber music: the Piano Trio in B Minor, the Variations and Epilogue for two pianos, and the Sonata No. 1 in E Minor for Violin and Piano. After 1916 just a few small chamber pieces appeared (both original and arrangements) as well as that deliberate Baroque imitation, the Sonata No. 2 in E Major for Violin and Piano (1921). The composition of both the Piano Trio in B Minor and the Violin Sonata No. 1 had begun prior to 1913, while the composer was still living in England.

One might well wonder why, since the string quartet was still the most prestigious (as well as the most common) medium of chamber music at the time, Willan did not produce a string quartet himself. A glance at the list of his major chamber works cited above will show that they all involve the piano. Amongst Willan's many unfinished manuscripts dating from his pre-1913 England days there are fragments of a Piano Quartet in A Minor (titled "The Heroic"), a Piano Trio in D Minor and two more sonatas for violin and piano, all adding to the list of chamber works involving the piano. Was Willan, in fact, like Schumann and some other Romantic composers, more at home in composing for chamber ensembles which included the rich sonorities of the piano than for the more ascetic medium of the string quartet? This may well be true. A pertinent factor here might be Willan's acknowledged admiration for the music of Brahms at the time he was working on these pieces, and the fact 
that for a while he had studied piano with a noted authority on the piano music of Brahms, Evlyn Howard-Jones.

If Willan did not find the medium of the string quartet congenial to his musical idiom it was not for want of trying. An examination of the composer's unfinished manuscripts from the first decade of the century reveals that he may have attempted as many as four different string quartets during that time. Two of these attempts, thirty measures of an "Energico" movement in G minor and eight measures of an "Allegro energico" in $\mathrm{D}$ minor are of little importance, though the $\mathrm{D}$ minor opening starts promisingly enough:

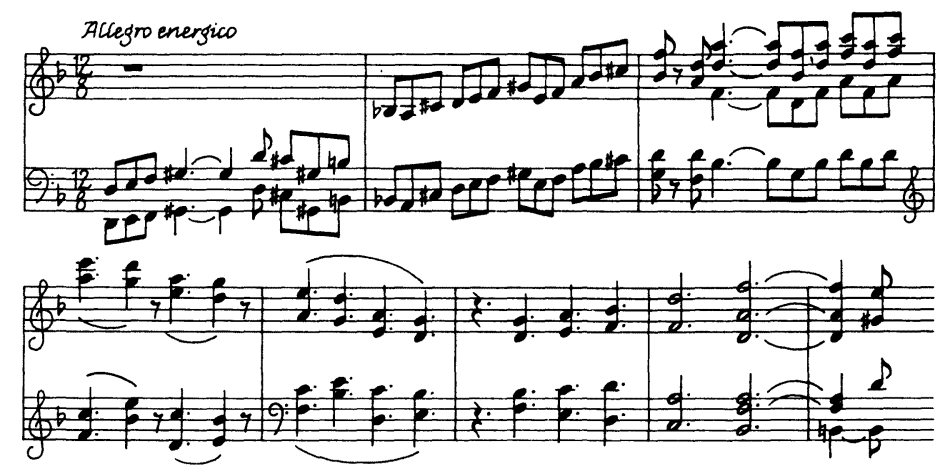

Example 1

The other two attemps involve a sizeable amount of music for several movements (unfortunately none of them completed) intended for string quartets in $\mathrm{E}$ minor and $\mathrm{C}$ minor.

In the Healey Willan Catalogue Giles Bryant (1972) lists four unfinished movements as constituting an unfinished String Quartet in E Minor (B.109): Allegro energico, Adagio, Lento e lugubre, and Finale (Rondo). He then states that it is "not certain" that the Lento e lugubre belongs to the quartet. I would go further and declare that neither the Lento nor the Finale belong, since they are both in C minor and it is highly unlikely that Willan at this stage of his career (1903-05) would have had the first two movements in E minor and the last two in $\mathrm{C}$ minor all in the same work! It is much more likely that the above movements were intended for two different quartets, and the following discussion of the music will proceed on this assumption. 
There are no less than eight unfinished versions of the first movement, Allegro energico, of the String Quartet in E Minor: four for string quartet (one dated 1903), two for piano trio, one for organ and one for piano. Of the four versions for string quartet only one is near to completeness and is titled "Phantasy for Two Violins, Viola and Cello" rather than "String Quartet." It might well be the earliest version. ${ }^{1}$ Some 200 measures long, it seems to sketch the outline of the complete movement, but often the measures are filled only by a single melodic line (especially in the second half) and it is not really possible to achieve a full knowledge of the movement from this. None of the other three string-quartet versions go any further than the arrival of the second subject in the exposition of the movement, but to that point they seem to correspond (save for a few changes here and there) to the music of the "Phantasy." Of the two versions for piano trio, the one dated 1905 consists of only a dozen measures, while the other goes as far as the second subject of the exposition. The organ version is only twenty measures, but enough is there to show that Willan might have made this movement into an effective organ piece if he had wished. The version which exhibits the most complete picture of the music is the one for piano, and that is the version which will be used here as the basis for examination. A lengthy paper could be written on the comparison of the eight versions of this movement, for, though the general outline of the music is similar in all of them, there is some variation in detail, and a study of the changes in lay-out necessitated by the various performing media would be instructive for any composition student.

The piano version of the Allegro energico gives the first 125 measures of this sonata-form movement - all of the exposition and most of the development. Thus all the materials on which the movement is built are present. Unlike many of Willan's other sonata-form movements, there is no slow introduction and the exposition starts right off with a vigorous and rather Brahmsian first subject. 


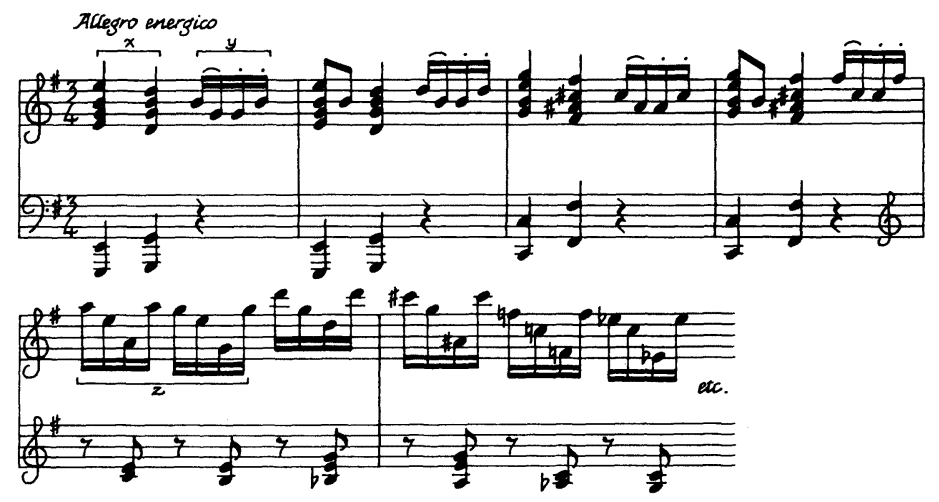

Example 2

The little figure marked $\lcm{y}$ in Example 2 was a favorite with Willan at this time and turned up in many of his instrumental works of this period and later. After some subsidiary material the opening theme is repeated, making a ternarystructured opening paragraph. The short bridge passage is in Willan's "marcia funebre" style, such as would later appear in the "Lament" from the dramatic cantata Cleopatra (B.1) of 1907 and the "Tuba Mirum" from the unfinished Requiem (B.61) of 1914-18.

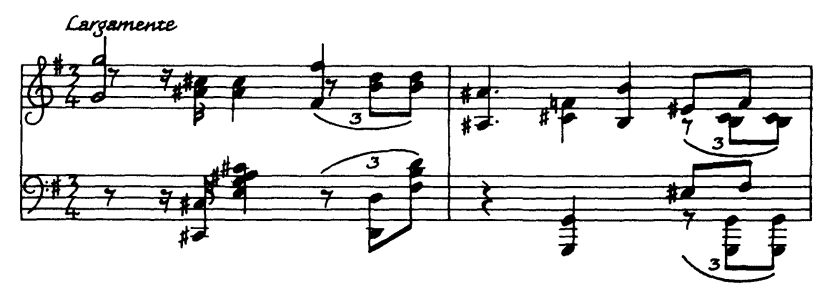

Example 3

The lyrical second subject is in the expected dominant key of B major:

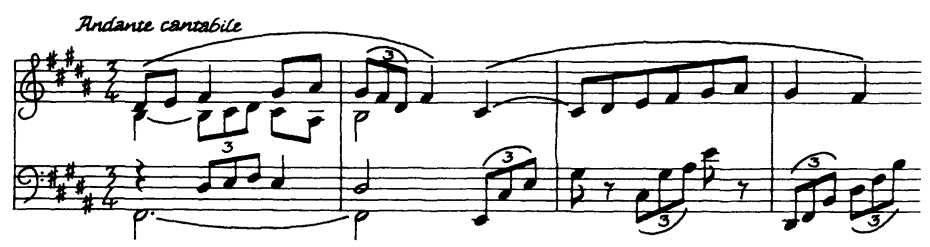

Example 4 
The development section starts in $\mathrm{F}$ major and moves over a wide range of tonalities, including $E$ flat major and $G$ flat major. It begins with ten measures in slow tempo (lento), and then resumes the pace of the opening (allegro). The material used for development is all taken from the three main figures of the first subject (Example 2): namely the two-chord motive $(x)$, the group of four sixteenth notes $(y)$, and the broken-chord pattern (z). The development breaks off at measure 125; how much longer it would have been is hard to say. ${ }^{2}$ The exposition is eighty measures long, which leaves sixty-five measures for the development. This music is well suited for the piano and would have made a good first movement of a piano sonata. Perhaps this was the reason the movement was never completed for string quartet: namely that - despite four attempts - the composer could not fully reconcile his material with the medium and felt the need for the presence of the piano.

The Adagio in E Major, which is presumed to have been intended to be the slow movement for the String Quartet in E Minor, was also left unfinished at this time (though all the material upon which the later finished version would be based was present). It is a beautiful piece of music, and Willan returned to it twenty-five years later to finish it as a separate piece for string quartet with the title of Poem. ${ }^{3}$ The Poem, lasting about eight minutes, is Willan's only completed original piece for string quartet. Even here the medium of the string quartet does not seem to have satisfied the composer, for in 1959 he rewrote the Poem for full string orchestra. Certainly the latter version gives fuller expression to the lushness of the musical style than the one for four solo strings.

In structure the Poem is in arch form (A B C $B^{\prime} A^{\prime}$ ), and the musical material on which each of the three different section is based is shown below.

Section A:

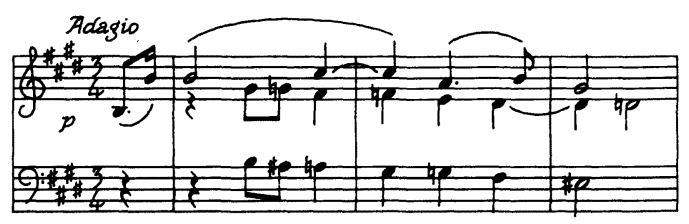


Section B:

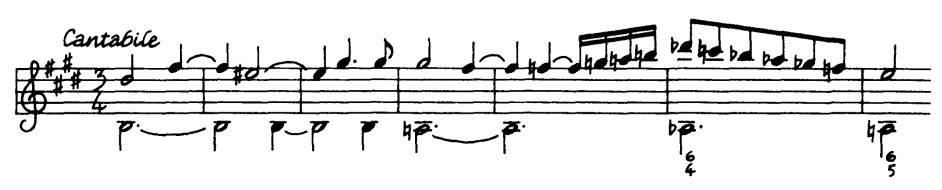

Section C:

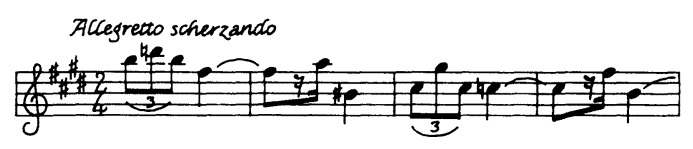

Example 5

Sections $\mathrm{B}^{\prime}$ and $\mathrm{A}^{\prime}$ are not exact repetitions of Sections $\mathrm{A}$ and $\mathrm{B}$, indeed $B^{\prime}$ is considerably shortened. The overall tonal scheme might be shown as follows:

Section A: E major

Section B: G sharp minor, B major

Section C: starts in B minor, finishes in $C$ sharp major

Section $B^{\prime}$ : D flat major

Section $A^{\prime}$ : E major

The remaining early unfinished string quartet movements by Willan are all in $\mathrm{C}$ minor and were probably intended to be part of a projected quartet in that key. The Lento e lugubre, listed by Bryant (1972:49) as a "slow" movement and possibly part of the E Minor Quartet is not really a slow movement at all. There are two incomplete versions and a sketch for this music, one version admittedly breaking off after twenty-one measures of slow music. The other version, however, backed up by the sketch, shows that this twenty-odd measures of Lento e lugubre is merely the slow introduction for a sonata-allegro movement (the latter being marked "allegro energico" in the score and "allegro feroce" in the sketch). As such I believe that this music is the intended first movement for a String Quartet in C Minor. It is further possible that the Lento in $C$ Minor numbered B.110 in the Healey Willan Catalogue was intended to be the slow movement of this quartet and that the Finale-Rondo listed under B.109 was to be the last movement. Since no sketches for a scherzo in string-quartet score have been discovered it is conceivable that these three movements (Lento 
e lugubre: Allegro energico, Lento, Finale-Rondo) would have constituted the complete quartet.

The probable first movement of the unfinished String Quartet in C Minor is composed up to the beginning of the recapitulation and, since it shows the whole of the development section, is in a more complete state than the first movement of the E Minor Quartet. The slow introduction, marked "Lento e lugubre," commences as follows:

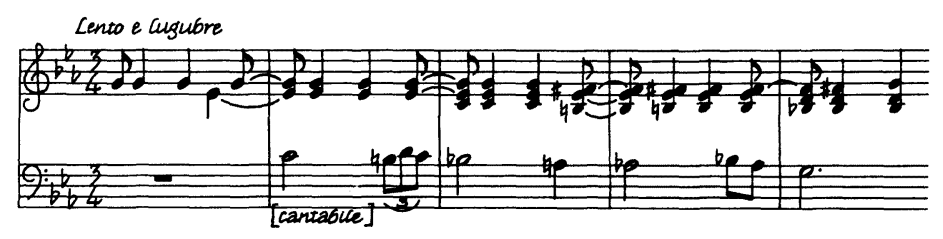

Example 6

The exposition of the Allegro energico opens with this theme:

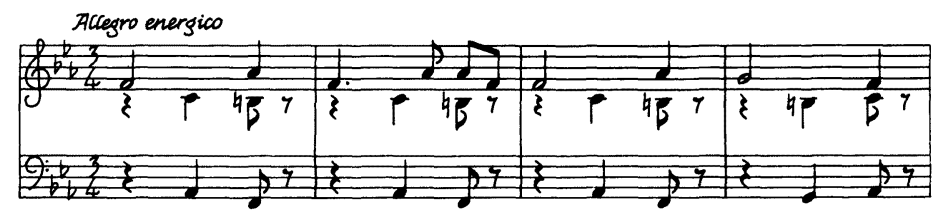

Example 7

This is extended at some length, becoming the basis of the bridge section. The second subject then appears in the relative major (E flat):

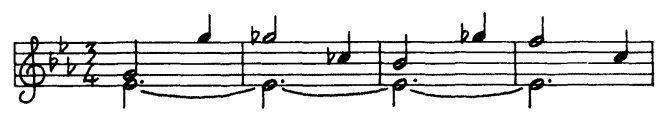

Example 8

This theme and its subsequent treatments seem to look forward to the main subject of the first movement of the Sonata No. 1 in E Minor. Subjects I and II are then developed together for thirty-two measures till the codetta is reached: 


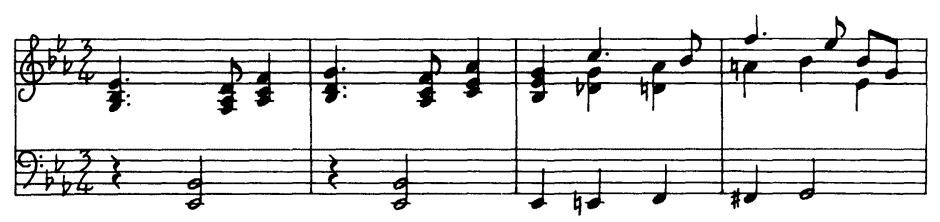

Example 9

The development section proper then leads off with a further treatment of the codetta motive, starting in B major. Other tonalities soon appear with the development of figures derived from the first and second subjects, and some canonic treatment is shown. The development section returns to B major for its climax, after which it slips rather smoothly via a chromatic sleight-of-hand (of the kind Willan could handle so well) back into the home tonality of $\mathrm{C}$ minor and the recapitulation (of which only four measures were written). The music for this movement seems to be better suited for the string-quartet medium than that of the first movement of the E Minor Quartet.

A possible intended slow movement for this String Quartet in $\mathrm{C}$ Minor might be a twenty-six-measure fragment in $\mathrm{C}$ minor marked "Lento" (B.110). This music later became the basis for the Adagio in B Minor for Violin and Piano, called Sonata No. 3 (1922). The twenty-six-measure fragment provides two of the main motives of the later work:

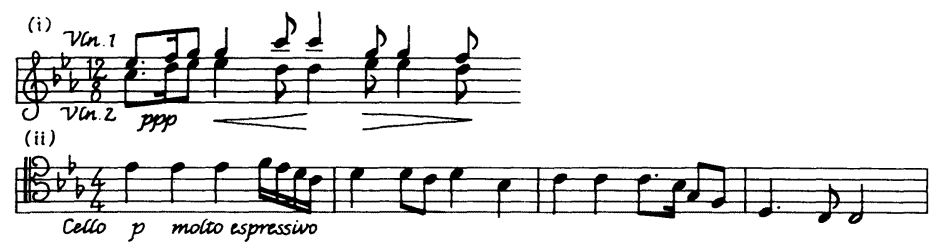

Example 10

Of the Rondo-Finale in C Minor only twenty-five measures of sketch exist. From this it is possible to determine only two things: (i) the movement was to begin with five measures of "quasi recitative" for full quartet and (ii) the rondo theme would be seven measures in length: 


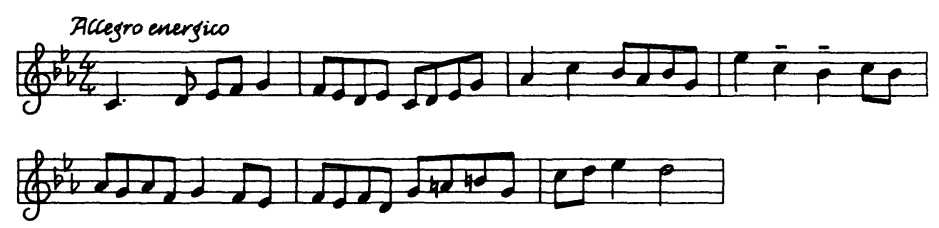

Example 11

These unfinished string quartets in E minor and C minor of ca. 1905 are interesting in that they show little of the influence of Wagner (which became apparent in such works as Cleopatra of 1907); here the influence seems to be more that of Brahms and the turn-of-the-century English school, with some input from the French. It is strange that Willan did not finish at least the first movement of the C Minor Quartet; since he got as far as the end of the development section the major task of composition was accomplished. We can be grateful that both the unfinished slow movements became the basis for important later works.

After these early attempts Willan seems to have abandoned the idea of composing a formal string quartet. In 1941, however, at a concert of Willan's music given at the Malloney Galleries in Toronto on November 20, Three Pieces for String Quartet were performed. These pieces were titled "Prelude," "Scherzo," and "Poem." The "Poem" is obviously the work of that name previously discussed. Scores for the "Prelude" and "Scherzo" have not been found, and I think that these were possibly arrangements of the first two of the six short pieces for organ published in 1910 (later to become the Miniature Suite for organ). This is particularly probable in the case of the "Scherzo," since it is known that in 1943-44 Willan made an arrangement for string orchestra (score missing) of the "Scherzo" movement of the Miniature Suite, and this arrangement might well have evolved from an earlier one for string quartet (i.e., the Poem).

To conclude, let us go back to the question posed at the beginning of this essay: "Why did Willan not complete a string quartet?" It certainly could not have been from a lack of fluency in counterpoint (and linear writing in general) since Willan had developed an enviable contrapuntal mastery quite early in his career (as is evidenced in his magnificent Prelude and Fugue in C Minor for Organ of 1908, one of the greatest of all his works). Was it because he was having problems with sonata form? An 
examination of the unfinished manuscripts of both symphonic and chamber works dating from the first years of this century might indicate this, since many of them get only as far as the exposition and then bog down and fizzle out during the development section. Yet if there was a problem here it was soon overcome, as witness the powerful and well-wrought Epilogue in D Minor for Organ of 1908 and the fine opening movements of the Piano Trio in B Minor and the Violin Sonata No. 1.

The answer probably lies in the fact that the period in which Willan was most interested in composing chamber music was one which came before his more ascetic period of missae brevi and motets, a period during which his imagination flowed with richly romantic musical ideas carrying on in the traditions of Brahms and Wagner. As was pointed out earlier, the nature of these musical ideas seemed to make them more suitable for chamber works employing the full sonorities of the piano rather than the leaner and more exposed textures of the string quartet. The pure, "string quartet" style probably inhibited Willan to some degree. Likewise, the only one of his quartet movements to be eventually finished - the Poem - is more successful in its later, fuller-sounding version for string orchestra. On the other hand, after his coming to Canada he enjoyed a close personal relationship with the members of the Blachford Quartet, two of whom performed the string parts in his Piano Trio several times. Had Willan chosen to write a string quartet there is little doubt that the Blachford Quartet would have performed it for him and he could have gained experience from this which was not always available to a composer in Canada at that time.

After ca. 1920, when Willan began writing music in a more austere style, he preferred to write in this manner for voices rather than instruments, as his musical focus became more church-centered. Later, during his years at the University of Toronto, when he returned to his interest in instrumental composition, it was to the symphony and the comparative opulence of the symphony orchestra that he turned rather than to the more limiting horizons of the string quartet.

Thus, for all these reasons, one might conclude that Healey Willan gave up his quest for a string quartet simply because he did not find the medium congenial to his creative musical thought. In this he was probably wiser than Verdi - who wrote one anyway! 


\section{NOTES}

1. It would certainly appear to be earlier than the piano version, since changes made by the composer to the manuscript in the development section of the "Phantasy" correspond to what appears in the development section of the piano piece.

2. There is not enough relationship between this development section and that in the "Phantasy" to make any judgement.

3. One of the manuscript versions of this piece carries the caption, Celtic Sketch No. 1; this would indicate that at one time Willan had planned to write a series of pieces for string quartet under the title of "Celtic Sketches." The quotation from W.B. Yeats, "And evening full of linnet's wings," at the head of the score would also appear to be part of this "Celtic" aspect.

\section{REFERENCES}

Bryant, G.

1972: Healey Willan Catalogue. Ottawa: National Library of Canada. 